\title{
Trabeculectomy versus Scheie's operation: a comparative retrospective study in open-angle glaucoma in Kenyans
}

\author{
NIEK J. A. BAKKER AND S. I. MANKU* \\ From the Eye Unit, Department of Surgery, Medical School, University of Nairobi
}

SUMMARY A comparative retrospective study was performed on 39 patients with open-angle glaucoma in whom the right eye was subjected to Scheie's operation, the left to trabeculectomy. Trabeculectomy without the use of additional therapy or reoperation brought the intraocular pressure to under $22 \mathrm{mmHg}$ in $80 \%$ of the cases compared with $74 \%$ treated by Scheie's operation. Reduction of visual acuity postoperatively was 4 times more frequent with Scheie's operation than with trabeculectomy. A report on a second group of patients in whom 47 trabeculectomies were performed is also given.

In the majority of Kenyan patients with open-angle glaucoma conservative treatment is out of the question, as irregular supplies of drugs, inconstant application, and insufficient follow-up make it unlikely to succeed. Therefore filtration surgery is the rule when visual field loss is observed. Although the first reports on trabeculectomies in black populations were conflicting (Chatterjee and Ansari, 1972; Welsh, 1972) more recently Freedman et al. (1976) and David et al. (1977) described good results in 80 and $91.6 \%$ of their cases respectively. In considering results of any kind of surgery, apart from the particular technique used, other factors have a role, such as the proficiency of the surgeon, the social class of the patient, and the quality of the postoperative treatment and care.

The usual method of filtration surgery in the Kenyatta National Hospital in Nairobi was Scheie's procedure. Before introducing trabeculectomy we considered a comparative study in the local situation was required, the results of which are reported here together with those of a study solely of trabeculectomy. These results may be a guideline for eye surgeons in most developing countries.

\section{Materials and methods}

In contrast to other studies the open-angle glaucoma in our patients is not necessarily uncontrolled. As

*Present address: 41 Gordon Avenue, Hamilton 2303, New South Wales, Australia.

Correspondence to Dr N. J. A. Bakker, Sporkenhout 2, Geldrop, The Netherlands. conservative treatment was doomed to failure, patients with open-angle glaucoma seen between February 1975 and September 1977 who showed visual field loss and in whom bilateral surgery was advisable were subjected to Scheie's operation in the right eye and trabeculectomy in the left eye.

There were 48 patients in this first group, 9 of whom were excluded because the follow-up was less than 3 months. The remaining 39 were Kenyan Africans, 31 males and 8 females. The age of the patients varied from 20 to 75 years, with a mean of 55.4 years. Follow-up was from 3 to 26 months, with a mean of 11.8 months. The second group consisted of patients for whom bilateral surgery was not indicated or for whom enthusiastic but unbiased surgeons did a trabeculectomy on both eyes. In this group 77 operations were performed, 47 of which, on 33 patients, could be followed up for a minimum of 3 months. Again all were Kenyan Africans, 21 males and 12 females, varying in age from 25 to 73 years with a mean of 51.7 years. The follow-up was between 3 and 33 months, with a mean of 19.6 months.

In the first group only primary surgery was performed. In the second group 4 failures of earlier filtration surgery were included. All patients were phakic. Postoperatively all intraocular pressures were measured with an applanation tonometer by the first author.

The technique used for Scheie's operation was as described by Scheie (1958). Trabeculectomy was performed as indicated by Cairns using the modification given by Watson (1972). Magnification of $\times 2$ was used in the trabeculectomies. All operations 
were performed under local anaesthesia. Patients were mobilised on the first postoperative day and discharged on the fifth. Post operative treatment consisted of antibiotic, steroid, and cycloplegic eye ointment 3 times a day.

The intraocular pressure was considered controlled when it was below $22 \mathrm{mmHg}$ at the latest visit without additional medication. The visual acuity was recorded as worse when, in comparison with the preoperative level, there was a drop of 2 or more lines on Snellen's chart or of steps in the range $6 / 60,5 / 60$ to $3 / 60,2 / 60$ to $1 / 60$, hand movements, perception of light, and no perception of light.

\section{Results}

Table 1 presents the results of group 1, that is, the comparative study between Scheie's operation and trabeculectomy, as well as those of group 2, the trabeculectomy-only group. The mean intraocular pressure postoperatively has been divided into 2 groups, those that were controlled and those that were not.

In group 1, out of the 39 eyes subjected to Scheie's operation 9 had a flat anterior chamber for more than 3 days, resulting in uncontrolled pressures in 2 eyes and in lowered sight in 3 . In 3 eyes treated by this operation a hyphaema occurred, resulting in 2 failures, 1 ending in endophthalmitis. One eye on this operation needed repair of a leaking bleb 3 months after the operation. In the 39 eyes treated by trabeculectomy a flat anterior chamber lasting a week caused a drop in visual acuity. One eye had vitreous loss, causing the visual acuity to diminish and leaving the pressure increased. In 47 eyes in group 2 treated by trabeculectomy there were 2 cases of hyphaema which cleared without sequelae.

Table 1 Intraocular pressure with standard deviation in $\mathrm{mmHg}$ pre-and postoperatively and results of surgery in groups 1 and 2

\begin{tabular}{|c|c|c|c|}
\hline \multirow[b]{3}{*}{ Number of operations } & \multicolumn{2}{|l|}{ Group 1} & \multirow{2}{*}{$\begin{array}{l}\text { Group } 2 \\
\text { Trabec. }\end{array}$} \\
\hline & Scheie's & Trabec. & \\
\hline & 39 & 39 & 47 \\
\hline IOP preop. & $34 \cdot 9 \pm 9 \cdot 1$ & $33 \cdot 8 \pm 10 \cdot 0$ & $33 \cdot 4 \pm 6 \cdot 7$ \\
\hline $\begin{array}{l}\text { IOP postop. } \\
\text { (controlled) } \\
\text { (uncontrolled) }\end{array}$ & $\begin{array}{l}13 \cdot 6 \pm 5 \cdot 0 \\
31 \cdot 8 \pm 6 \cdot 3\end{array}$ & $\begin{array}{l}16 \cdot 2 \pm 3 \cdot 4 \\
28 \cdot 1 \pm 7 \cdot 2\end{array}$ & $\begin{array}{l}15 \cdot 7 \pm 2 \cdot 4 \\
30 \cdot 7 \pm 2 \cdot 9\end{array}$ \\
\hline $\begin{array}{l}\text { IOP controlled } \\
\qquad(<22 \mathrm{mmHg})\end{array}$ & $29(74 \%)$ & $31(80 \%)$ & $40(85 \%)$ \\
\hline $\begin{array}{l}\text { Visual ac. same or } \\
\text { better }\end{array}$ & $31(80 \%)$ & $37(95 \%)$ & $41(87 \%)$ \\
\hline
\end{tabular}

Table 2 Change in intraocular pressure between $3 \mathrm{rd}$ and 15th month after surgery $(\mathrm{mmHg} \pm \mathrm{SD})$

\begin{tabular}{llll}
\hline & \multicolumn{2}{l}{ Group 1 } & Group 2 \\
\cline { 2 - 4 } & \multicolumn{1}{c}{ Scheie's } & Trabec. & Trabec. \\
\cline { 2 - 4 } Number of operations & 6 & 10 & 19 \\
\hline $\begin{array}{l}\text { IOP at } 3 \text { months } \\
\begin{array}{l}\text { IOP at } 15 \text { months or } \\
\text { later }\end{array}\end{array}$ & $11.7 \pm 4.6$ & $14.4 \pm 6.5$ & $18.2 \pm 2.5$ \\
$\begin{array}{l}\text { Change in mean IOP } \\
\text { Chan }\end{array}$ & -0.9 & $15.4 \pm 4.4$ & $15.9 \pm 2.5$ \\
\hline
\end{tabular}

Vitreous loss occurred in 2 eyes, 1 of which lost sight and ended with high pressure.

In patients with controlled intra-ocular pressure who could be followed up for 15 months or longer and for whom sufficient data were available the course of intraocular pressure was followed. Table 2 gives the change in $\mathrm{mmHg}$ between visits at 3 months approximately and at 15 months or more postoperatively.

\section{Discussion}

When, as in the second group, 27 out of 77 operations have a follow-up period of less than 3 months, or sometımes no follow-up at all, the question is whether it was the failures or the successes who did not return. Seventy-six patients who seldom, if ever, turned up for control visits were invited by letter to report to the glaucoma clinic, from which request we had almost a $50 \%$ response. Eighteen of those fell into the Scheie-trabeculectomy group. The pressures were regulated in $72 \%$ and the visual acuity was as before or better in $80 \%$. In the trabeculectomy group 18 patients, altogether 21 operated eyes, had a regulated pressure in $90 \%$ and no decreased visual acuity in $85 \%$. Although again the fate of those who did not reply was unknown, it became more likely that they had either died or could not afford the transport costs to the hospital.

There is little reason to believe that in this study defaulting influenced the results. Whether acceptance of a minimum follow-up of 3 months would be sufficient was investigated by comparing the intraocular pressures at postoperative control visits at 3 months and 15 months or more. For the Scheie's operations as well as for the trabeculectomies, fluctuations were limited to a few $\mathrm{mmHg}$. Again, of the total of 23 eyes in this study in which ultimately the pressure was not controlled the failure was found within 3 months in 19 eyes. In 2 patients it was noticed at their first visit at 6 months after surgery and in only 2 was it detected at 12 months. 
Having dealt with the most obvious reasons for incorrect interpretation of the results, we can consider the main object of this study. In a comparative study Scheie's procedure controlled the intraocular pressure in $74 \%$ of the cases versus $80 \%$ in trabeculectomy. The difference is insignificant, and there would be little reason for preferring one procedure to the other had it not been shown that patients after Scheie's operation have a 4 times higher risk of ending with a decreased visual acuity postoperatively, mainly due to lens opacities. We believe there is a difference between the cases in which postoperatively increased intraocular pressure is due merely to insufficient drainage and those in which the problem is caused by surgical complications. The latter accounted for 4 out of 10 uncontrolled intraocular pressures in eyes treated by Scheie's operation, for 1 out of 4 trabeculectomies in group 1, and for another 1 out of 7 in those in group 2 . The higher failure rate that consequently can be expected in repeat surgery may be another reason for selecting trabeculectomy in preference to Scheie's operation.

We thank Mr P. M. Sinabulya, Dr P. J. Onyango, and Dr A. Manguyu for their assistance in performing surgery, and $\mathrm{Mr}$ J. Owino for the technical assistance.

\section{References}

Chatterjee, S., and Ansari, M. W. (1972). Microsurgical trabeculectomy in Ghana. British Journal of Ophthalmology, 56, 783.

David, R., Freedman, J., and Luntz, M. H. (1977). Comparative study of Watson's and Cairns's trabeculectomies in a Black population with open-angle glaucoma. British Journal of Ophthalmology, 61, 117.

Freedman, J., Shen, E., and Ahrens, M. (1976). Trabeculectomy in a Black American glaucoma population. British Journal of Ophthalmology, 60, 573.

Scheie, H. G. (1958). Retraction of scleral wound edges. American Journal of Ophthalmology, 45, 220.

Watson, P. G. (1972). Surgery of the glaucomas. British Journal of Ophthalmology, 56, 299.

Welsh, N. H. (1972). Trabeculectomy with fistula formation in the African. British Journal of Ophthalmology, 56, 32. 